\title{
Burnout in Postgraduate Trainees and Consultants working in Psychiatry Departments of Teaching Hospitals in Lahore, Pakistan
}

\section{Aysha Butt, ${ }^{1}$ Sara Rehman, ${ }^{2}$ Minahil Rahman ${ }^{3}$}

\begin{abstract}
Objective: To gauge the prevalence of burnout among postgraduate trainees and consultants working in psychiatry department, Services Hospital Lahore, Pakistan.

Methods: 31 trainee and consultant psychiatrists in Services Hospital Lahore, Pakistan participated in this cross-sectional study. Abbreviated Maslach Burnout Inventory (aMBI) measured burnout. It consisted of 9 items, relating to emotional exhaustion, depersonalization and personal accomplishment. Each item is scored on a seven-point Likert scale. For Emotional Exhaustion and Depersonalization, higher scores predicted greater burnout; Personal Accomplishment demonstrated the opposite, hence its scores were inverted. Participants with moderate scores in 2 or more dimensions were identified as suffering from burnout syndrome. Data was analyzed by SPSS 25.0.

Result: Mean age of participants was $34.87 \pm 8.06$ years. $52 \%$ were female. $58 \%$ were consultants, with average experience of 7 years; $61 \%$ practiced in more than one place. $32.3 \%$ of participants had burnout syndrome. Emotional Exhaustion subscale showed the highest scores i.e. $7.06 \pm 3.43$. $71 \%$ of participants demonstrated moderate or high burnout in this scale. Average Depersonalization score was $2.94 \pm 2.42$, while that for Personal Accomplishment was 3.29 \pm 2.25 .

Conclusion: A significant portion of the sample reported moderate and high level of emotional exhaustion. On the contrary, we found low levels of depersonalization in the sample. Most psychiatrists reported adequate levels of personal achievement. These results are reassuring because, despite the presence of emotional burnout, psychiatrists still have capacity to empathize and provide adequate patient care.

Key Words: burnout, psychiatry, trainees, consultants, Lahore, Pakistan

How to cite: But. A., Rahman S., Rahman Minahil. Burnout in Postgraduate Trainees and Consultants working in Psychiatry Departments of Teaching Hospitals in Lahore, Pakistan. Esculapio 2021;71(01):83-87

DOI: https://doi.org/10.51273/esc21.2517117
\end{abstract}

\section{Introduction}

$\mathrm{B}$ urnout is defined as a syndrome comprising emotional exhaustion, depersonalization and reduced personal accomplishment. ${ }^{1}$ It is often a side effect of medical training and practice, due to a myriad of stressors associated with clinical work. Stressors pertinent to psychiatry can include hostile patients, patient suicide and working with victims of violence. Psychiatrists who lose a patient to suicide

\footnotetext{
1. Aysha Butt

3. Minahil Rahman

2. Sara Rehman

1-3. Department of Psychiatry, Services Hospital, Lahore.
}

Correspondence:

Dr. Aysha Butt, Department of Psychiatry, Services Hospital, Lahore.

Email:doctoraisha@yahoo.com

Submission Date:

1st Revision Date:

Acceptance Date:
03-02-2021

$12-02-2021$

$02-03-2021$ may be plagued by guilt. ${ }^{2}$ Psychiatry as a specialty is emotionally taxing; empathy and maintaining objectivity while being emotionally available for patient can be draining. The chronicity of psychiatric conditions and delayed progress in patients can lead to feelings of helplessness and frustration. ${ }^{3}$

Consequences of burnout are faced by both the psychiatrist and the patient. As the clinician fails to cope, psychological manifestations of burnout emerge, including depression, anxiety and substance abuse., Suicidal ideation has also been reported by trainees. ${ }^{6}$ Rich and Pitts found psychiatrists to have twice the risk of committing suicide. ${ }^{7}$ Burnout may compromise the quality of care, increase the probability of mistakes, decrease performance, lead to a sense of inadequacy and cause a spillover of work-related stress in family life. ${ }^{8}$ Some doctors may, even if unwittingly, avoid particular patients or situations. ${ }^{2}$ The psychological 
and work-related ramifications of burnout are alarming, and it poses a considerable threat to physician wellbeing.

Physician well-being has long been a neglected matter. Doctors are an essential pillar of the health care system. They put their duties before their mental and physical health, which suffer consequently. Burnout is an urgent issue which must be addressed. While previously research has been carried out to measure burnout in specialties like medicine, surgery and gynecology, we found a dearth of research relating to psychiatric trainees and consultants. In the present study we will gauge the prevalence of burnout in this population and attempt to bridge the prevailing gap in data.

\section{Methods}

A cross-sectional study was conducted over a period of one month, from 11 September to 11 October 2020. The participants were postgraduate trainees and consultants working in psychiatry department, Services Hospital Lahore, Pakistan. The sample size for this research was 31 . Participants were chosen via convenience sampling and informed consent was obtained from each subject.

A structured questionnaire was utilized to record demographic characteristics and intensity of burnout. The self-reported questionnaire was administered via Google Forms, owing to the ongoing covid-19 pandemic. The demographic characteristics are shown in Table 1. Burnout was measured by the Abbreviated Maslach Burnout Inventory (aMBI), as shown in Table 3. It is a valid and reliable measure. ${ }^{9,10}$ It measured three dimensions of burnout: emotional exhaustion, depersonalization and personal accomplishment. Abbreviated Maslach Burnout Inventory consisted of 9 items: questions 3, 4, 7 were related to emotional exhaustion; questions $2,5,8$ were related to depersonalization; questions 1, 6, 9 were related to personal accomplishment. Each item was responded to on a Likert scale, ranging from "Never" (scored as 0 ) to "Everyday" (scored as 6). The score of each dimension ranged from $0-18$. For the first 2 dimensions higher scores predicted greater burnout, while the third dimension demonstrated the opposite. Thus, the scores of personal achievement subscale were inverted so that higher scores reflected greater burnout, allowing for uniform interpretation of scores in all three scales. The Abbreviated Maslach Burnout Inventory defines burnout as moderate scores in 2 or more dimensions. Data was entered into and analyzed by SPSS 25.0. For quantitative variables, mean and standard deviations were calculated. For qualitative variables, frequency and percentage distributions were generated.

Ethical approval was obtained from the institutional review board, RefNo. IRB/2020/692/SIMS.

\section{Results}

Thirty-one participants responded to the questionnaire over a period of one month. The demographic characteristics are shown in Table 1 . The mean age of the participants was $34.87 \pm 8.06$ years. $52 \%$ of the respondents were female. $58 \%$ were working as consultants, with an average of approximately 7 years of experience; $61 \%$ of them practiced in more than one place. $46 \%$ of the psychiatric trainees were PG-2, while $30 \%$ were PG-3. The average scores of each subscale are shown in Table 2. Emotional exhaustion subscale showed the highest scores i.e. $7.06 \pm 3.43$. $64 \%$ of the participants demonstrated moderate burnout in this scale. Low burnout was exhibited in the depersonalization scale by $90 \%$ and in the personal achievement scale by $74 \%$ of the participants. $10(32 \%)$ participants demonstra-ted moderate burnout in at least 2 subscales, fulfilling the criterion for burnout as defined by Abbreviated Maslach Burnout Inventory.

\section{Discussion}

Table 1: Demographic Characteristics

\begin{tabular}{llc}
\hline Demographic Characteristics & Number & \% \\
\hline Age (years) & $34.87 \pm 8.06$ & - \\
Sex & & \\
Male & 15.00 & 48.39 \\
Female & 16.00 & 51.61 \\
Working as: & & \\
Trainee: & 13.00 & 41.94 \\
PG1 & 1.00 & 7.69 \\
PG2 & 6.00 & 46.15 \\
PG3 & 4.00 & 30.77 \\
PG4 & 2.00 & 15.38 \\
Consultant & 18.00 & 58.06 \\
Duration of Practice (years): & $6.83 \pm 5.83$ & \\
Do you practice in more than one & & \\
place? (for consultants) & & \\
Yes & 11.00 & 61.11 \\
No & 7.00 & 38.89 \\
\hline
\end{tabular}


Table 2: Average Scores and Frequency of Burnout in each Subscale

\begin{tabular}{lcccccc}
\hline \multicolumn{1}{c}{ Scale } & Average score (SD) & \multicolumn{2}{c}{ Low Burnout } & \multicolumn{2}{c}{ Moderate Burnout } & High Burnout \\
\hline & & $\mathrm{n}$ & $\%$ & $\mathrm{n}$ & $\%$ & $\mathrm{n}$ \\
Emotional Exhaustion & $7.06 \pm 3.43$ & 9 & 29.03 & 20 & 64.52 & 2 \\
Depersonalization & $2.94 \pm 2.42$ & 28 & 90.32 & 3 & 9.68 & 0 \\
Personal Achievement & $3.29 \pm 2.25$ & 23 & 74.19 & 8 & 25.81 & 0 \\
(inverted scores) & & & & & & \\
\hline
\end{tabular}

Table 3: Frequency of Responses to Individual Items of the aMBI by the Participants

\begin{tabular}{|c|c|c|c|c|c|c|c|c|c|c|c|c|c|c|}
\hline \multirow[t]{2}{*}{ Items } & \multicolumn{2}{|c|}{$\begin{array}{l}\text { Every } \\
\text { day }\end{array}$} & \multicolumn{2}{|c|}{$\begin{array}{c}\text { A few } \\
\text { times } \\
\text { a week }\end{array}$} & \multicolumn{2}{|c|}{$\begin{array}{l}\text { Once } \\
\text { a } \\
\text { week }\end{array}$} & \multicolumn{2}{|c|}{$\begin{array}{c}\text { A few } \\
\text { times } \\
\text { a month }\end{array}$} & \multicolumn{2}{|c|}{$\begin{array}{l}\text { Once } \\
\text { a month } \\
\text { or less }\end{array}$} & \multicolumn{2}{|c|}{$\begin{array}{l}\text { A few } \\
\text { times } \\
\text { a year }\end{array}$} & \multicolumn{2}{|c|}{ Never } \\
\hline & $\mathrm{N}$ & $\%$ & $\mathrm{~N}$ & $\%$ & $\mathrm{~N}$ & $\%$ & $\mathrm{~N}$ & $\%$ & $\mathrm{~N}$ & $\%$ & $\mathrm{~N}$ & $\%$ & $\mathrm{~N}$ & $\%$ \\
\hline $\begin{array}{l}\text { I deal very effectively with the } \\
\text { problems of my patients }\end{array}$ & 20 & 64.52 & 6 & 19.35 & 5 & 16.13 & 0 & - & 0 & - & 0 & - & 0 & - \\
\hline $\begin{array}{l}\text { I feel I treat some patients as if they } \\
\text { were impersonal objects }\end{array}$ & 0 & - & 2 & 6.45 & 1 & 3.23 & 4 & 12.90 & 6 & 19.35 & 9 & 29.03 & 9 & 29.03 \\
\hline $\begin{array}{l}\text { I feel emotionally drained from my } \\
\text { work }\end{array}$ & 0 & - & 7 & 22.58 & 1 & 3.23 & 9 & 29.03 & 5 & 16.13 & 8 & 25.81 & 1 & 3.23 \\
\hline $\begin{array}{l}\text { I feel fatigued when I get up in the } \\
\text { morning and have to face another } \\
\text { day on the job }\end{array}$ & 0 & - & 2 & 6.45 & 3 & 9.68 & 8 & 25.81 & 10 & 32.26 & 7 & 22.58 & 1 & 3.23 \\
\hline $\begin{array}{l}\text { I've become more callous } \\
\text { towards people since I took this job }\end{array}$ & 0 & - & 0 & - & 3 & 9.68 & 0 & - & 5 & 16.13 & 11 & 35.48 & 12 & 38.71 \\
\hline $\begin{array}{l}\text { I feel I'm positively influencing other } \\
\text { people's lives through my work }\end{array}$ & 12 & 38.71 & 8 & 25.81 & 5 & 16.13 & 6 & 19.35 & 0 & - & 0 & - & 0 & - \\
\hline $\begin{array}{l}\text { Working with people all day is really a } \\
\text { strain for me }\end{array}$ & 0 & - & 2 & 6.45 & 2 & 6.45 & 10 & 32.26 & 2 & 6.45 & 10 & 32.26 & 5 & 16.13 \\
\hline $\begin{array}{l}\text { I don't really care what happens to } \\
\text { some patients }\end{array}$ & 0 & - & 0 & - & 0 & - & 0 & - & 3 & 9.68 & 5 & 16.13 & 23 & 74.19 \\
\hline $\begin{array}{l}\text { I feel exhilarated after working closely } \\
\text { with my patients }\end{array}$ & 7 & 22.50 & 11 & 35.48 & 6 & 19.35 & 3 & 9.68 & 2 & 6.45 & 2 & 6.45 & 0 & - \\
\hline
\end{tabular}

According to our data, $32 \%$ of the psychiatrists suffered from burnout syndrome. The constant demand of emotional labour may put psychiatrists at risk, more so than other specialties. A Canadian study reported that $21 \%$ of the psychiatric residents experienced burnout. ${ }^{11}$ Martini et al. found $40 \%$ of psychiatry trainees to be suffering from burnout. ${ }^{12}$ An Irish study found $75 \%$ of child psychiatrists were struggling with burnout; however, since this study utilized the Copenhagen Burnout Inventory it is harder to draw comparisons. ${ }^{13}$

Our sample showed higher levels of burnout in the domain of emotional exhaustion: $71 \%$ had moderate or high burnout. This is slightly higher than the scores presented by Kumar et.al, where almost $67 \%$ experienced emotional exhaustion. ${ }^{14}$ Fülöp et al. found high emotional exhaustion among psychiatrists to be $32.8 \%{ }^{15}$ Emotional exhaustion can render the physician unable to emotionally connect with their patients, as their emotional resources are expended. To the question "I feel I treat some patients as if they were impersonal objects", $26 \%$ of the participants reported that they experienced this a few times a year, while $16 \%$ reportedly experienced this once a month or less. Almost $32 \%$ and $26 \%$ reported that the thought of going to work was draining, once month or less and a few times a month respectively. $32 \%$ of the respondents found working with people all day to be a strain a few times a month; a similar percentage reported to experience this once a month or less.

The depersonalized physician treats their patient with indifference. Our sample reported low levels of depersonalization; almost $10 \%$ were revealed to have moderate burnout in this scale and none reported high burnout. A study in New Zealand found that $26 \%$ and $13 \%$ of the psychiatrists had moderate and high burnout in this scale, respectively. ${ }^{14}$ Similarly, another research found $29.9 \%$ of the psychiatrists struggled with depersonalization. ${ }^{15}$ The questions "I don't really care what happens to some patients" and "I've become 
more callous towards people since I took this job" were overwhelmingly dismissed by respondents in our sample. This shows that despite the high prevalence of emotional burnout, the clinicians are still capable of caring for, and about, the patient. However, we must treat these figures with cautious optimism.

Personal accomplishment scores were inverted, so that higher scores corresponded to greater burnout, similar to emotional exhaustion and depersonalization. It is reassuring that a majority of psychiatrists reported high levels of sense of achievement. Burnout In Consultants in Ireland Study (BICDIS) showed similar results regarding the dissonance among the Emotional Exhaustion and Personal Accomplishment scales. ${ }^{16}$ In our sample, $64 \%$ believed that they deal very effectively with the problems of their patients. Most psychiatrists felt that they have a positive impact on their patients' lives.

Our study demonstrates optimistic findings regarding sense of accomplishment and empathy in psychiatrics. However, it is clear that physician wellbeing is an issue we must contend with in a timely manner, or we could be faced with dire consequences relating to physician health and patient care in future. Spickard suggests that physicians should be encouraged to take part in self-care activities, including spiritual activities and spending time with loved ones. ${ }^{17}$

This study used a self-reported measure which, although convenient, can introduce inaccuracies in the obtained data. However, we have used the Abbreviated Maslach Burnout Inventory as a tool to merely screen for the possibility of burnout and detect those at risk. Our results have been derived from a sample chosen by convenience sampling. This could impart some level of sampling bias to our results. Moreover, our limited sample size makes it difficult to make solid inferences. Our study does not attempt to find correlations between workplace and personal variables and burnout. Further research on burnout, consisting of a nationwide sample, focusing on variables associated with physician burnout is critical.

\section{Conclusion}

$32 \%$ of the psychiatrists were afflicted by burnout syndrome in our sample. A significant portion reported moderate and high level of emotional exhaustion; on the contrary, we found low levels of depersonalization to be prevalent in the sample. Most psychiatrists reported adequate levels of personal achievement. These results are reassuring because, despite the presence of emotional burnout, psychiatrists still have the capacity to empathize and provide adequate patient care.

\section{Conflict of Interest: None}

\section{References}

1. Kumar S. Burnout in psychiatrists. World Psychiatry. 2007 Oct;6(3):186-9.

2. Coverdale J, Balon R, Beresin E V., Brenner AM, Louie AK, Guerrero APS, et al. What Are Some Stressful Adversities in Psychiatry Residency Training, and How Should They Be Managed Professionally? Acad Psychiatry. 2019;43(2):145-50.

3. Bermak GE. Do psychiatrists have special emotional problems? Am J Psychoanal. 1977 Jun;37(2):141-6.

4. Muzafar Y, Khan HH, Ashraf H, Hussain W, Sajid H, Tahir M, et al. Burnout and its Associated Factors in Medical Students of Lahore, Pakistan. Cureus. 2015; $7(11)$.

5. Patel RS, Bachu R, Adikey A, Malik M, Shah M. Factors related to physician burnout and its consequences: A review. Vol. 8, Behavioral Sciences. MDPI Multidisciplinary Digital Publishing Institute; 2018.

6. Tateno M, Jovanović N, Beezhold J, Uehara-Aoyama K, Umene-Nakano W, Nakamae T, et al. Suicidal ideation and burnout among psychiatric trainees in Japan. Early Interv Psychiatry. 2018 Oct 1;12(5): 935-7.

7. Rich CL, Pitts FN. Suicide by psychiatrists: a study of medical specialists among 18,730 consecutive physician deaths during a five-year period, 1967-72. J Clin Psychiatry. 1980 Aug 1;41(8):261-3.

8. Suñer-Soler R, Grau-Martín A, Flichtentrei D, Prats M, Braga F, Font-Mayolas S, et al. The consequences of burnout syndrome among healthcare professionals in Spain and Spanish speaking Latin American countries. Burn Res. 2014;1(2):82-9.

9. Gabbe SG, Melville J, Mandel L, Walker E. Burnout in chairs of obstetrics and gynecology: Diagnosis, treatment, and prevention. In: American Journal of Obstetrics and Gynecology. Mosby Inc.; 2002. p. 601-12.

10. Riley MR, Mohr DC, Waddimba AC. The reliability and validity of three-item screening measures for burnout: Evidence from group-employed health care practitioners in upstate New York. Stress Heal. 2018 Feb 1;34(1):187-93.

11. Kealy D, Halli P, Ogrodniczuk JS, Hadjipavlou G. 
Burnout among Canadian Psychiatry Residents: A National Survey. Can J Psychiatry. 2016; 61(11): 732-6.

12. Martini S, Arfken CL, Churchill A, Balon R. Burnout comparison among residents in different medical specialties. Acad Psychiatry. 2004 Sep;28(3):240-2.

13. Mcnicholas F, Sharma S, Oconnor C, Barrett E. Burnout in consultants in child and adolescent mental health services (CAMHS) in Ireland: a cross-sectional study. BMJ Open. 2020;10(1):1-9.

14. Kumar S, Fischer J, Robinson E, Hatcher S, Bhagat RN. Burnout and job satisfaction in New Zealand psychiatrists: A national study. Int J Soc Psychiatry. 2007;53(4):306-16.

15. Fülöp E, Devecsery Á, Hausz K, Kovács Z, Csabai M. Relationship between empathy and burnout among psychiatric residents. New Med. 2011;2011Janua(4):143-7.

16. Margiotta F, Crudden G, Byrne D, Doherty AM. Prevalence and co-variates of burnout in consultant hospital doctors: burnout in consultants in Ireland Study (BICDIS). Ir J Med Sci. 2019;188(2):355-64.

17. Spickard A, Gabbe SG, Christensen JF. Mid-career burnout in generalist and specialist physicians. Vol. 288, Journal of the American Medical Association. American Medical Association; 2002. p. 1447-50.
Authors Contribution
BA: Conception \& Initial Writing of Manuscript
RS,RM: Data Collection
RS,RM: Statistical Analysis
RS: Drafting, Revision 